
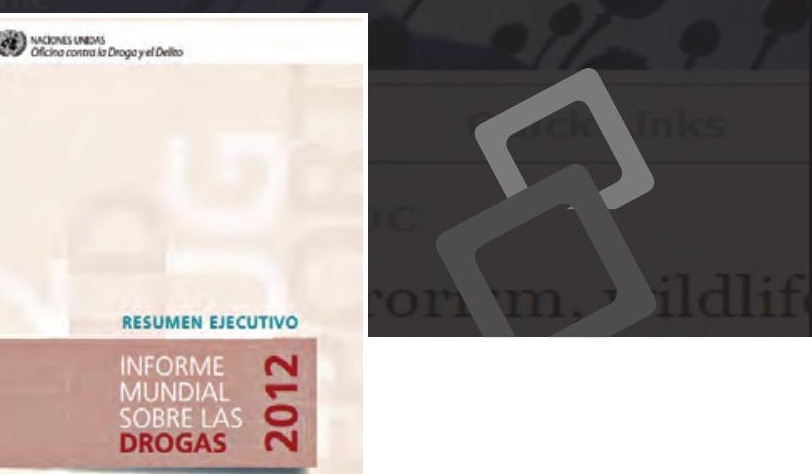

\title{
Informe Mundial sobre las Drogas 2012
}

La Oficina de las Naciones Unidas contra la Droga y el Delito (UNODC por sus siglas en inglés) presentó en el 2012 un informe que solamente demuestra lo descontrolada o poco valorada que se encuentra la situación de las drogas y sus efectos colaterales a nivel mundial. Desde su prefacio anuncia un número desconsolador: para el año 2010 unas 230 millones de personas adultas en el mundo, es decir, el 5\% de la población mundial, consumen o han consumido recientemente drogas ilícitas. De esta cifra se desprenden una cantidad elevada de consumidores problemáticos, y por ende, constituyen un problema social en todos los estratos que componen a la sociedad.

El documento se divide en dos partes; la primera trata sobre estadísticas y análisis de tendencias recientes de los mercados de drogas ilícitas. La segunda parte trata sobre el problema contemporáneo de la droga, haciendo una descripción elemental de sus características, pautas y fuerzas motrices. Luego presenta unas conclusiones breves a efectos de generar conciencia sobre un problema que demanda cada vez mayor atención.

En la primera parte destaca que las drogas más consumidas en el mundo son las ilícitas, de entre las cuales goza con una imparable tendencia al alza, el cannabis. Estadísticamente presenta popularidad a nivel mundial, pero la zona de mayor consumo es el hemisferio occidental. En segundo lugar se encuentran las drogas sintéticas (la cuales presentan una leve alza en comparación con los años anteriores); en tercer lugar la cocaína y sus derivados; en cuarto lugar los opioides y en último los opiáceos (por su complicada distribución en la mayoría del territorio occidental). Las estadísticas están presentadas de forma detallada y al mismo tiempo se describen los móviles a través de los cuales las drogas llegan al consumi. dor promedio.

Por otra parte, también el documento trata sobre los perfiles usuales en el consumidor promedio, las tendencias económico-sociales en los países que presentan mayor consumo, brindando así una herramienta básica 
de medición para el interesado en los aspectos demográficos. De este elemento cabe destacar que estadísticamente son más los hombres que mujeres en cuanto al consumo, llegando por momentos a $80 \%$ de hombres por $20 \%$ de mujeres, según el año y la región.

En la segunda parte trata sobre los aspectos cualitativos que en alguna medida determinan el nivel de consumo problemático a nivel mundial. Aspectos como el consumismo, el conformismo, la desesperanza de un mejor futuro, la caída de los ideales de una mejor sociedad, son el alguna medida los detonantes para que los jóvenes en la actualidad, no tengan ningún reparo moral en comenzar a incursionar en el mundo de las drogas ilícitas, independientemente de las consecuencias que esto atraiga. También en estos aspectos, occidente muestra un mayor deterioro, según el informe, aunque oriente alcanza niveles alarmantes en los últimos años. El daño colateral presenta consecuencias que resultan en un déficit mundial mucho más grande que todas las incautaciones, inversiones en programas de salud y recuperación, e incluso, el combate mismo al narcotráfico. En ese sentido, el informe es útil para comprender la necesidad del Ilamado al no consumo de las drogas tanto legales como ilegales; sin caer en ningún tipo de doble moralidad, el documento tiene el mérito de presentar cómo afectan los consumidores problemáticos en todos los ámbitos, augurando una posible etapa de insostenibilidad social.

Las conclusiones pueden considerarse una advertencia importante, que por momentos suena en tono profético: de seguir la situación tal y como se encuentra (certeris paribus), independientemente de los esfuerzos por fiscalizar e incautar las drogas ilícitas, su uso, distribución y consumo, tenderá a la alza a nivel mundial, en las próximas décadas: los más afectados serán los jóvenes, aunque los consumidores actuales vayan envejeciendo; según el informe, el problema posee raíces sociales y culturales, que solamente demuestran lo erosionada que se encuentra la sociedad a nivel mundial; sobre todo en los entornos urbanos, y en la medida en que se acorte la brecha con lo rural, el consumo se masificará, mientras los países no promuevan políticamente el vivir a plenitud los fundamentales derechos humanos.

Oficina de las Naciones Unidas Contra la Droga y el Delito Informe Mundial sobre drogas 2012 Naciones Unidas, Viena Tomado de: http://www.unodc.org/documents/southerncone//Topics_drugs/ WDR/2012/Executive_summary_Spanish.pdf

Las sinopsis de los documentos web estuvieron a cargo de Edwin Edgardo González Rodríguez 